GRADIATION\&APPLICATIONS

ISSN 2466-4294 (online) | rad-journal.org

Vol. 2 | Issue 3 | pp. 192 - 199, 2017

doi: 10.21175/RadJ.2017.03.039

Original research paper

\title{
HOMO/HETEROGENEITY OF CS-137 VERTICAL DISTRIBUTION WITHIN PLOUGH HORIZONS OF CULTIVATED CHERNOZEMS - 30 YEARS AFTER CHERNOBYL ACCIDENT*
}

\author{
Tatiana Paramonova $^{{ }^{* *}}$, Vladimir Belyaev², Olga Komissarova1, Maxim Ivanov ${ }^{2}$ \\ ${ }^{1}$ Faculty of Soil Science, Lomonosov Moscow State University, Russia \\ ${ }^{2}$ Faculty of Geography, Lomonosov Moscow State University, Russia
}

\begin{abstract}
Vertical distribution of Cs-137 in cultivated chernozems of the Plavsk radioactive hotspot has been investigated, with the emphasis on the plough horizon. It is shown that the commonly expected complete homogeneity of the isotope vertical distribution within the plough and old-plough horizons of cultivated chernozems is not always achieved. Incomplete homogeneity can be explained by the application of different cultivation techniques for various crops within the crop rotation system employed. Important observation is that in cases of relatively shallow cultivation (such as disking to 12-15 cm depth) the largest root biomass content remains within the upper $10 \mathrm{~cm}$ layer, while maximum Cs-137 content is shifted downwards to underplough layer at 10-20 cm depths. At the same time, traditional cultivation with plough layer rotation and mixing to the $20-25 \mathrm{~cm}$ depth results in more uniform Cs-137 distribution through the plough layer, while layer of active root uptake of mineral matter for row crops shifts from the soil surface downward. Therefore, it can be recommended that the systematic monitoring of cultivated topsoil conditions based on preliminary assessment of Cs-137 vertical profile distribution, taking into account agrotechnical specifics of different crops within the crop rotation, must be carried out in order to obtain the reliable assessment of the soil radioecological status.
\end{abstract}

Key words: Arable soils, caesium-137 ( ${ }^{137 C s)}$, Chernobyl accident, profile distribution, radioactive contamination, soil pollution, vertical migration

\section{INTRODUCTION}

The shape of the Cs-137 depth profile distribution is one of the important parameters to be accounted for when assessing environmental consequences of the radioactive contamination, including the Chernobyl fallout-affected areas. It determines the up-to-date superposition of contaminated topsoil layer and vegetation rhizosphere, indicates radiocaesium migration potential with soil waters and its transfer into groundwater. It is widely accepted that one of the important distinctive features of the Cs-137 behavior in mineral soils is its ability to perform specific and irreversible sorption in interpocket spaces and wedgeshaped marginal widenings of crystal lattice of certain clay and mica minerals [1] - [3]. Parent material of the chernozem soils of the Russian Plain is in most cases represented by loessy loams with mineral composition enriched in clay minerals of the illite and montmorillonite groups. Therefore, the irreversible sorption property of Cs-137 is especially prominent for these soils. More than $70 \%$ of its total inventory bound to the clay fraction because of the strong grain size selectivity of Cs-137 fixation [4].
Principal processes of the isotope vertical migration in native chernozem soils include diffusion, convection in soil solutes, lessivage, and bioturbation by soil mesofauna and vegetation roots [4]. All the above processes are characterized by low intensity. Therefore, Cs-137 downward penetration from the surface into the soil profile for undisturbed soils over the 3 decades since the Chernobyl accident was very limited. The International Atomic Energy Agency (IAEA) manual for express-sampling of soils in radioactively contaminated uncultivated areas recommends that the upper $10-15 \mathrm{~cm}$ of the topsoil should be sampled in undisturbed soils of natural ecosystems [5].

A different situation takes place on cultivated lands where agrogenic turbation processes (rotational ploughing, disking, harrowing, shelling and other cultivation operations) cause the rapid decline of Cs137 topsoil content and averaging of its concentration across the plough layer depth. As a result, the total isotope inventory in cultivated soils remains the same, but the distribution shape of the depth profile changes profoundly. The substantial decrease of the Cs-137 concentration in upper $10 \mathrm{~cm}$ layer is essential, as that is the layer where the most active matter exchange between soil and crop roots takes place. It was,

\footnotetext{
* The paper was presented at the Fifth International Conference on Radiation and Applications in Various Fields of Research (RAD 2017), Budva, Montenegro, 2017.

tparamonova@soil.msu.ru
} 
T. Paramonova et al., Homo/heterogeneity of Cs-137 vertical distribution..., Rad. Applic., 2017, 2, 3, 192-199

therefore, recommended to introduce periodical (once per several years) deeper plantage ploughing as a reasonably effective rehabilitation measure for significantly contaminated lands [6], [7]. Even more effective, in terms of contaminated land rehabilitation, is a single run of extremely deep rotational ploughing immediately after a radioactive contamination incident with burying the upper $5-\mathrm{cm}$ layer to $30-50 \mathrm{~cm}$ depth and subsequent standard cultivation to the depth not exceeding 20-25 cm [6].

Experiments involving the artificial introduction of atmospheric aerosol pollutants to the soil surface with the subsequent topsoil layer mixing (performed manually with a spade) showed that the Cs-137 concentration in mixed 20-cm layer becomes reasonably uniform just within 3 mixture cycles [8]. It is, therefore, generally accepted that Cs-137, in continuously cultivated soils, becomes relatively uniformly distributed through the entire depth of a plough horizon within several years after a contamination event, due to its regular mixing and homogenization by various cultivation operations (rotational ploughing, disking, harrowing, etc.). Hence, it seems sufficient for radioecological investigations of agrocenosis to carry out an integral sampling to the plough layer depth [5] with the subsequent analysis of mean Cs-137 concentration for the entire plough layer and calculation of the isotope inventory based on its concentration, plough layer thickness and bulk density.

The main purpose of the present study was to test the applicability limits of approximation of the uniform Cs-137 depth distribution in plough horizon of cultivated chernozems and assess the actual shapes (if different from uniform) of the isotope vertical distribution in the area of the European Russia strongly contaminated by the Chernobyl fallout with 3 decades passed since the contamination event.

\section{OBJECTS AND METHODS}

Investigations of the Cs-137 vertical profile distribution parameters were carried out in 2012-2016 period within the so-called Plavsk radioactive contamination hotspot territory (Tula Region, about $250 \mathrm{~km}$ south from Moscow) - one of the areas characterized by the most significant Chernobyl fallout contamination within the European Russia. Initial fallout contamination by Cs-137 for the Plavsk hotspot area was evaluated within a range of $185-555 \mathrm{kBq} / \mathrm{m}^{2}$. Forecasts show that radioactive contamination in the area will remain detectable until the end of $21^{\text {st }}$ Century [9]. Despite the relatively high Cs-137 pollution level, most of agricultural lands of the area have remained cultivated ever since the Chernobyl accident in 1986 due to the high natural fertility and productivity level of the chernozem soils dominant in the area (some $15-20 \%$ of the cultivated areas were temporarily abandoned between late 1990 s and 2000s, but rather as a result of general economic disorder than for radioecological safety reasons).

Case study sites were selected within the central part of the Plavsk radioactive hotspot occupying the surfaces of water-divide hilltops or low-gradient upper hillslopes unaffected by soil erosion processes. All sites were selected within long-term arable fields with crops representing most of the typical cultures of the zonal crop rotation, including wheat, barley, potato, corn, amaranth, soya beans, and leguminous plants. Dominant soils for all the case study sites are represented by the Chernozems leached (WRB-2014 Luvic Chernozems [10]) characterized by heavy clay loam texture, significant thickness of productive organic horizons $(\mathrm{A}+\mathrm{AB}$ varies within a range of 64-78 cm), high humus content (6-7\%), neutral reaction ( $\mathrm{pH}$ range 6.5-7.2) and very well-developed structure of topsoil horizons determining optimal bulk density of 1.1-1.2 $\mathrm{g} / \mathrm{cm}^{3}$ [11].

Several approaches were employed to test the uniformity of the present vertical distribution of Cs-137 in cultivated chernozems of the case study sites after a detailed description of soil sections. These included: a) sampling of all genetic soil horizons described within a particular soil section; b) detailed depth-incremental sampling from fixed square surface area $\left(25 \times 25 \mathrm{~cm}^{2}\right)$ and depth intervals 3-5 $\mathrm{cm}$ by scrapes to total sampling depth of 40-50 cm; c) rough depth-incremental sampling from fixed circular surface area and depth intervals $0-10,10-20$ and $20-30 \mathrm{~cm}$ from plough and old-plough horizons by cylindrical steel corer sampler (8.2 $\mathrm{cm}$ diameter, $425 \mathrm{~cm}^{3}$ volume). In case of the genetic soil horizons, the sampling volume of samples was not fixed, but the samples for soil bulk density determination were taken simultaneously using a 5 -cm diameter cylindrical steel sampler. Crosscontamination of soil samples was avoided by accurate cutting of separate soil cores and careful cleaning of the sampler.

Laboratory pretreatment of the soil samples included drying, grinding, 2-mm sieving and homogenization. Afterwards gamma-spectrometry measurements of the $\mathrm{Cs}-137$ content in representative subsamples were carried out by the Multirad gammaradiometer with the BDKS-63-01A detector (based on a hyperpure germanium crystal). The energy calibration was carried out using a $1 \mathrm{~L}$ Marinelli calibration source №470/5045 (Russian Federation) with Cs-137 activity $3800 \mathrm{~Bq}$ (01.04.2005) and standard reference calibration source №17.08.A (Russian Federation) with Cs-137 activity $1700 \mathrm{~Bq}$ (28.11.2008). The laboratory radioactive background with an empty Marinelli beaker was determined before every sample measurement to correct the net result. Subsamples were taken to fill the Russian standard geometry of the 120-ml "Denta" cylindrical plastic vessel (diameter $7.3 \mathrm{~cm}$, height $3.5 \mathrm{~cm}$ ) and the mass of each sample was $\approx 0.12-0.13 \mathrm{~kg}$. Spectra analysis and measurements processing was carried out using the "Progress 5.1" spectrometric analysis software package. The activity of each soil sample was counted for $1800 \mathrm{~s}$ and detected on the basis of the line $662 \mathrm{keV}$. Uncertainty in the Cs-137 specific activity determination did not exceed $10-15 \%$. In order to facilitate the comparison of all results obtained over the 5 -years field campaign of 2012-2016, all the measurements were subsequently recalculated to the date of the latest 2016 sampling results with account of the $\mathrm{Cs}-137$ radioactive decay rate.

In parallel with rough 10-cm depth-incremental soil sampling for Cs-137 specific activity and inventory, the 
T. Paramonova et al., Homo/heterogeneity of Cs-137 vertical distribution..., Rad. Applic., 2017, 2, 3, 192-199

analogous sampling was carried out from the same soil section for washing out the underground root biomass. Washing out of the roots from the sampled soil mass was carried out under pressurized tap water flow through a set of two sieves ( $1 \mathrm{~mm}$ and $0.25 \mathrm{~mm}$ mesh) until the completely clear flow was achieved. The underground (predominantly root) biomass acquired this way was oven dried under $80^{\circ} \mathrm{C}$ and weighed. Total biomass inventory in $\mathrm{kg} / \mathrm{m}^{2}$ was subsequently calculated for each of the three sampling layers (0-10, 10-20 and 20-30 cm).

For the entire 5-years field campaign of 2012-2016 fieldworks were carried out during the final vegetation period of cultural crops immediately prior to harvesting, in most cases - during a period between August $10^{\text {th }}$ and $25^{\text {th }}$. Soil samples were taken in triple replications: a) for genetic horizon sampling - from front and side walls of a single soil section; b) for rough 10-cm depth-incremental sampling - from three individual sections located randomly within a uniform elementary soil areal 5-15 $\mathrm{m}$ from each other; c) for detailed $3-5 \mathrm{~cm}$ depth-incremental sampling, three reference soil sections were selected on the morphologically typical flat watershed hilltops located several kilometers from each other, within the same small catchment with other case study sites. Triple replications were chosen due to previously Ivanov et al. demonstrated for the territory of Plavsk radioactive hotspot that 3 -samples averaging is suitable for the assessment of Cs-137 activity in soil with an inaccuracy of $25 \%$ and a confidence level more than 95\% [13].

Total amount of studied sites was 18, with 54 points of sampling and more then 200 individual samples. All the obtained results were later analyzed by the means of variation statistics.

\section{RESUlTS AND DisCUSSION}

\subsection{Integral vertical profile depth distribution of} the Cs-137 in cultivated chernozems

Morphological descriptions of soil sections in cultivated chernozems of the Plavsk radioactive hotspot showed that, although the typical structure of genetic horizons (Ap - Aop - A - AB - Bc - BCc - Cc) is reasonably uniform, the current cultivation depth represented by the Ap plough horizon varies substantially within a range of $10-30 \mathrm{~cm}$. That year-toyear variability largely depends on specific cultivation types applicable for different crops within the crop rotation. Main cultivation types employed for the dominant cereal crops (spring wheat, winter barley) include mainly shallow penetration techniques, such as disking, shelling, harrowing involving loosening, and the partial rotation of the upper topsoil layer is commonly limited to $10-12 \mathrm{~cm}$. Cultivation of corn and rapeseed usually involves traditional rotational tillage with depth of 20-25 cm. For potatoes, tillage depth can be increased to the present maximum of $27-30 \mathrm{~cm}$. In addition to the Ap horizon representative of the current cultivation practice, the underlying so-called oldplough horizon Aop is observed practically everywhere on the cultivated fields of the study area. It can be distinguished from the overlying current Ap horizon by increased bulk density, higher compaction and larger and rougher-shaped granular-blocky clods (agro peds), while from the underlying natural A horizon - by the distinctive abrupt boundary, in most cases with prominent compaction features along the plough sole shoe. Depth of the Aop horizon base in the studied soil sections varied between 28 and $30 \mathrm{~cm}$.

Genetic horizon sampling of the cultivated chernozems of the Plavsk radioactive hotspot and subsequent gamma-spectrometric analyses showed that until present depth of Cs-137 penetration into the soil profile does not exceed $30 \mathrm{~cm}$, meaning that $>98 \%$ of the isotope inventory is still stored within the agriculturally disturbed horizons Ap + Aop (Fig. 1). The data are consistent with observations of Lipatov et al. for the old-arable chernozems of Tula region [14]. Mean value of the Cs-137 activity concentration for all samples obtained from plough horizon is $454 \pm 52 \mathrm{~Bq} / \mathrm{kg}$ (330-626 Bq/kg), while for the Aop separately $-420 \pm 37 \mathrm{~Bq} / \mathrm{kg}$ (309-604 Bq/kg). Presence of the Aop horizon in all sampled sections and relative comparability of the Cs-137 concentration values in Ap and Aop horizons not only indicate the periodic deep rotational tillage for the row crops cultivation, but they also support the available information on the application of $30-\mathrm{cm}$ depth anti-contamination rehabilitation tillage immediately after the Chernobyl accident and contamination in April-May, 1986.

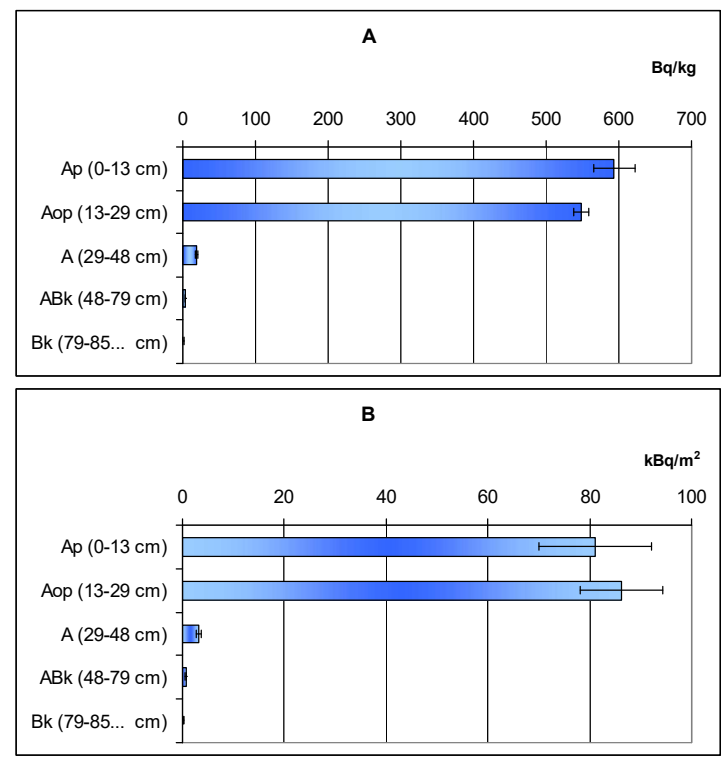

Figure 1. Typical profile distribution of the Cs-137 specific activity (A) and inventory (B) in cultivated chernozems of the Plavsk radioactive hotspot

In turn, depth distribution of the Cs-137 within the Ap + Aop horizons depends on actual cultivation types employed which profoundly impact the topsoil bulk density. In cases of minimal cultivation techniques causing just loosening of the upper 10-12 cm layer, a relatively larger percentage of the total Cs-137 inventory can be stored within the substantially denser Aop horizon (Fig. 1b). 
T. Paramonova et al., Homo/heterogeneity of Cs-137 vertical distribution..., Rad. Applic., 2017, 2, 3, 192-199

3.2. Vertical profile depth distribution of $\mathrm{Cs}-137$ within plough and old-plough horizons

The detailed depth-incremental sampling of the three reference soil sections in cultivated chernozems of the Plavsk radioactive hotspot showed similarly to the data presented above, a sharp decrease of Cs-137 content below the $30-\mathrm{cm}$ depth, with deeper isotope penetration not exceeding $2 \%$ of its total inventory. This again proves that the soil cultivation operations represent the most effective and important mechanism of the isotope redistribution within the topsoil ploughed layer. At the same time, natural processes of the Cs-137 vertical migration are characterized by much lower intensities, as their activity has not caused noticeable changes into the isotope vertical distribution profile shape even over the 30 years passed since the Chernobyl fallout.

At the same time, it is evident from the presented Cs-137 depth distribution profiles (Fig. 2) that there is no complete homogeneity of the isotope vertical distribution within the plough layers. Differences of Cs137 specific activities between individual depth increments within the Ap + Aop horizons reach the value of $50-80 \mathrm{~Bq} / \mathrm{kg}$ or $>10 \%$ in terms of the percentage of the total isotope inventory. It must also be noted that similar vertical microprofile variability values are observed for points with different total Cs137 inventory - from about 90 to $>225 \mathrm{kBq} / \mathrm{m}^{2}$.
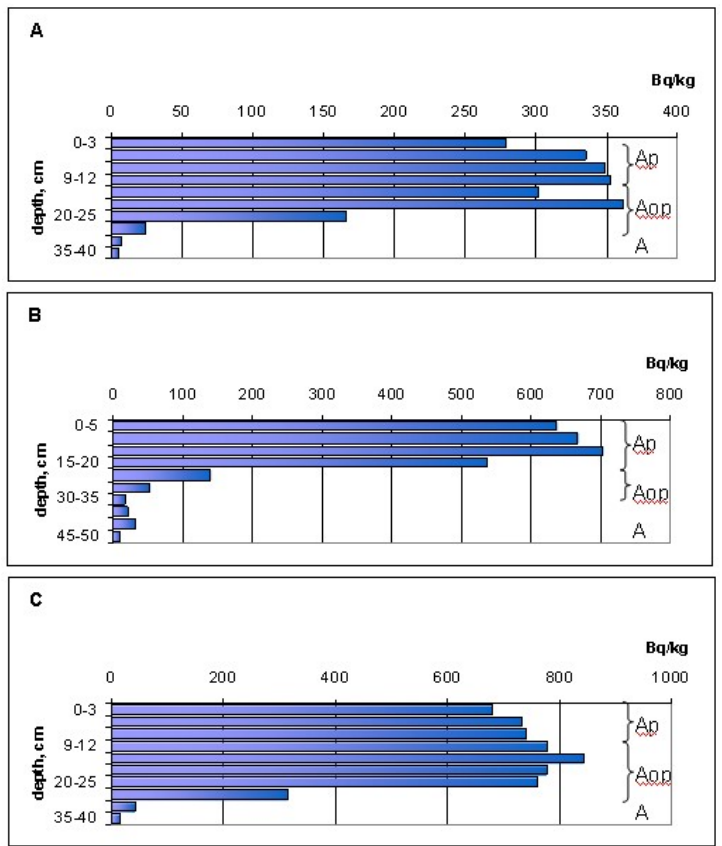

Figure 2. Detailed (3-5 cm) depth-incremental Cs-137 vertical profiles for the three reference soil sections of cultivated chernozems of the Plavsk radioactive hotspot sampled on watershed hilltops. Total Cs-137 inventory: A $-87.5 \mathrm{kBq} / \mathrm{m}^{2}$; $\mathrm{B}-225.6 \mathrm{kBq} / \mathrm{m}^{2} ; \mathrm{C}-113.4 \mathrm{kBq} / \mathrm{m}^{2}$

Heterogeneity of Cs-137 distribution within plough layer of arable soils has escaped the attention of the researchers. Even with experimental evidence in some studies presented in tables and figures the possible reasons are not discussed as a rule [14-16]. We suppose that the observed variability of the Cs- 137 vertical distribution within Ap + Aop horizons of cultivated chernozems of the Plavsk radioactive hotspot can be most reasonably explained by the combination of the two factors. The first is the local variability of convective-dispersion (filtration) penetration of the contaminated precipitation into the soil profile during the Chernobyl-associated fallout period in April-May 1986. The second is related to year-to-year changes of thickness of the cultivated layer and the type of cultivation technique during the post-Chernobyl period. The most important outcome is that the localization of the layer with highest Cs-137 content within the plough horizons varies substantially even for one arable field. The maximum isotope activity exceeding the mean value by $10-20 \%$ can be submerged to the depths of 12 to $18 \mathrm{~cm}$, which remain below the lower limit of the topsoil turnover, by cultivation in cases of cereal crops.

Most likely, the reason for deepening of the Cs-137 maximum activity from soil surface towards lower depths within the agriculturally disturbed layer is its relocation during the deep rehabilitation rotational tillage, undertaken soon after the contamination. Afterwards, normal agricultural cultivation practices resulted in a shallower layer turnover, in most cases not exceeding $25 \mathrm{~cm}$. Hence, the part of the soil profile containing higher Cs-137 concentrations could have remained stored below the regular cultivation layer limits but still within the total thickness of topsoil layer disturbed by tillage at least once since the Chernobyl fallout in 1986. In combination with compaction and increase density of this approximately $5-\mathrm{cm}(25-30 \mathrm{~cm}$ profile depth) layer this both resulted in its burying and largely prevented further downward migration of contaminated material through the even more compacted tillage sole shoe. Soil bulk density within the Ap horizon varies within a range of $0.65-1.17 \mathrm{~g} / \mathrm{cm}^{3}$ (mean value $0.92 \pm 0.11 \mathrm{~g} / \mathrm{cm}^{3}$ ), within the Aop horizon - 0.96-1.25 g/ $\mathrm{cm}^{3}$ (mean value $1.12 \pm 0.07 \mathrm{~g} / \mathrm{cm}^{3}$ ), i.e. it increases by about $20 \%$ within the old plough horizon.

On the other hand, the appearance of local smaller peaks in vertical Cs-137 distribution within genetically and morphologically uniform Ap and/or Aop horizons can be associated with shorter-term factors causing noticeable changes within the isotope semi-uniform microprofile depth distribution. It is difficult to determine the unambiguous causes of an observed heterogeneity. For example, the correlation analyses carried out on the obtained dataset has not shown significant relation at any level between Cs-137 activity and soil bulk density in the respective depthincremental layers $(\mathrm{r}<0.50$ under $\mathrm{P}=0.95)$. Besides, soil texture in different soil horizons and layers varies only slightly (Table 1) and it is unlikely that quantity or quality characteristics of clay minerals affect Cs-137 distribution within top of chernozem profile.

Thus, it cannot be argued that the local peaks of the isotope vertical distribution are also associated with layers of increased soil density and compaction, which could act as local geochemical barriers of mechanical (screen) or chemical (sorption) types with relatively increased capacities. 
T. Paramonova et al., Homo/heterogeneity of Cs-137 vertical distribution..., Rad. Applic., 2017, 2, 3, 192-199

Table 1. Composition of particle-size fractions in $30-\mathrm{cm}$ topsoil layer of cultivated chernozem of the Plavsk radioactive hotspot, \%

\begin{tabular}{|c|c|c|c|c|c|}
\hline \multirow{2}{*}{ Soil layer, cm } & \multicolumn{2}{|c|}{ Clay, mm } & \multicolumn{2}{c|}{ Silt, mm } & $\begin{array}{c}\text { Sand, } \\
\mathrm{mm}\end{array}$ \\
\cline { 2 - 6 } & $<0.0001$ & $\begin{array}{c}\text { 0.005- } \\
\text { o.0001 }\end{array}$ & $\begin{array}{c}\text { 0.01- } \\
\text { 0.005 }\end{array}$ & $\begin{array}{c}\text { 0.05- } \\
0.01\end{array}$ & $\begin{array}{c}0.25^{-} \\
0.05\end{array}$ \\
\hline O-10 cm & 10.3 & 32.2 & 15.4 & 42.0 & 0.1 \\
$10-20 \mathrm{~cm}$ & 10.2 & 31.5 & 15.1 & 43.0 & 0.3 \\
$20-30 \mathrm{~cm}$ & 10.4 & 31.3 & 15.2 & 42.7 & 0.3 \\
\hline
\end{tabular}

It is possible to assume that the observed heterogeneity of the Cs-137 vertical distribution in chernozem soils plough horizons can to certain extent be explained by the structural organization of pedons at the soil structure-aggregate level. For example, a relatively increased Cs-137 storage in the Aop horizon may be associated with its more stable structural aggregates in comparison to the upper $0-10$ (15) $\mathrm{cm}$ layer which is affected by the cultivation practically every year. Such regular disturbances cause the mechanical destruction of large soil aggregates with the noticeable decrease of their mean diameter from 11.9 to $6.1 \mathrm{~mm}$ - almost twice. Disaggregated finer mineral grains together with smaller water-resistant structureaggregate fractions of $0.5-2.0 \mathrm{~mm}$ were shown to demonstrate size-selective affinity to Cs-137 sorption, mainly due to the presence of clay minerals in their composition. At the same time, these fractions of both mineral grains and structural aggregates are much more vulnerable to remobilization by wind and water erosion, while the Ap horizon becomes enriched by coarser blocky clods with size $>10 \mathrm{~mm}$ with lower Cs137 activity mainly related to the lower effective surface area for its sorption [12]. The Aop horizon in contrast is characterized by the long-term existence of mediumsized stable soil aggregates with relatively higher Cs137 specific activities. Such differentiation can provide an additional mechanism and partial explanation for conservation of the isotope within stable soil aggregates and its relatively increased content within the Aop horizon.

\subsection{Intraseasonal control of Cs-137 distribution within the $30 \mathrm{~cm}$ cultivated chernozem topsoil layer under individual crop growing}

As a check on stability of Cs-137 distribution within the $30 \mathrm{~cm}$ topsoil layer of arable chernozem during single vegetation season the depth-incremental sampling from plough and old-plough horizons with depth intervals $0-10,10-20$ and $20-30 \mathrm{~cm}$ was conducted on the field with growing of winter wheat. Very similar mean characteristics of Cs-137 specific activities in sublayers were noticed for the period from May until August, i.e. from spring harrowing of soil until harvesting (Fig. 3). Even intraseasonal agrocultivation occuring in the end of June without soil conventional rotation had no visible influence on Cs137 distribution within microprofile.

Some increasing of Cs-137 mass-specific activities in the upper $0-10 \mathrm{~cm}$ and $10-20 \mathrm{~cm}$ chernozem layers according the August observations was more likely associated with heterogeneity of the radionuclide secondary spatial redistribution over short distances. At the same time relatively constant Cs-137 content in lower 20-30 cm layer was a distinguishing feature for all periods of observations.

As a whole it is possible to believe that for the separate field Cs-137 distribution within the plough horizon is more or less steady during a growing period.

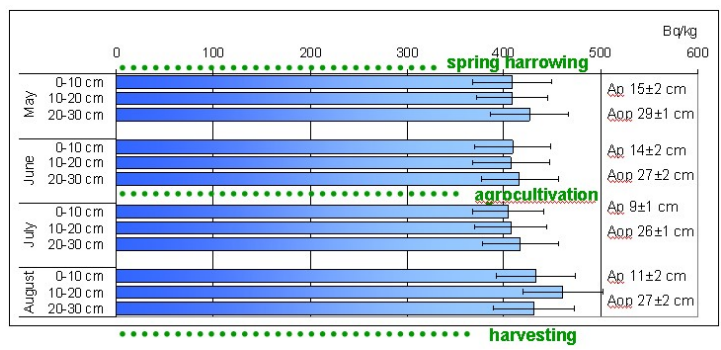

Figure 3. Distribution of Cs-137 specific activities in the 30 $\mathrm{cm}$ topsoil layer of cultivated chernozem during cultivation of winter wheat, the Plavsk radioactive hotspot

\subsection{Variability of vertical profile distribution of} Cs-137 within the plough horizons of cultivated chernozems caused by crop rotations

In order to clarify the question of stability or instability of localized vertical patterns of Cs-137 profile concentration zones within the cultivated chernozem soil plough layers, the rough $(10-\mathrm{cm})$ depthincremental soil sampling was repeated every year from 2012 to 2016 at the selected reference site situated on the flat interfluve surface within the Plavsk radioactive hotspot central part. Several different crops changed each other on the field over that period, including barley, soya bean, potato and corn. According to the morphological description of soil sections, Ap layer thickness varied between 8 and 24 $\mathrm{cm}$ from year to year. During crop rotation years when barley and soya bean were grown, shallow cultivation techniques were employed, while for corn and potato regular rotational tillage to the $20-25 \mathrm{~cm}$ depth took place. It must also be noted, however, that although cultivation for soya been immediately prior to sowing involves shallow harrowing or disking to 8-10 $\mathrm{cm}$ causing formation of distinctive current shallow Ap horizon, it can be preceded by deeper under-winter rotational tillage $(20-25 \mathrm{~cm})$ if the previous crop was cereals. Lower boundary of the Aop horizon was detected at depths of $24-30 \mathrm{~cm}$ proving that this particular field also underwent deep rehabilitation rotational tillage for radioecological purpose soon after the Chernobyl fallout in 1986. The Ap horizon mean bulk density varied from $0.97 \mathrm{~g} / \mathrm{cm}^{3}$ (under potato) to $1.23 \mathrm{~g} / \mathrm{cm}^{3}$ (under corn). The Aop horizon mean bulk density variability was very limited - from 1.25 to $1.30 \mathrm{~g} / \mathrm{cm}^{3}$, indirectly supporting the above statement of the relatively more stable structural-aggregate level organization of the old plough horizon material.

Taking into account the spatial and temporal variability of soil properties, the mean value of Cs-137 specific activity in upper $30-\mathrm{cm}$ topsoil layer $(\sim \mathrm{Ap}+\mathrm{Aop})$ of sampled cultivated chernozems of the study site (recalculated to the 2016 sampling date with account for radioactive decay rate in order to facilitate comparison between years) was $411 \pm 37 \mathrm{~Bq} / \mathrm{kg}$, mean total topsoil isotope inventory reached the value of 
T. Paramonova et al., Homo/heterogeneity of Cs-137 vertical distribution..., Rad. Applic., 2017, 2, 3, 192-199

$158 \pm 16 \mathrm{kBq} / \mathrm{m}^{2}$, with coefficients of variation of $16 \%$ and $18 \%$ respectively (for $\mathrm{P}=0.95$ ). Parameters of temporal variability of the isotope content in soil were generally close to range of spatial variability observed within each individual period of observation.

At the same time, the alternation of cultures within crop rotation and associated changes of agrotechnical approaches used for harvesting preceding crop, presowing, sowing and post-sowing cultivation practices noticeably impact vertical distribution of Cs-137 within plough layers (Fig. 4). It is especially evident when comparing cereals and row crops. For example, barley cultivation is associated with the minimal shallow soil disturbance to the depth not exceeding $10 \mathrm{~cm}$. Under such conditions, peak of the Cs-137 maximum specific activities shifted substantially downwards to the depths of $10-20 \mathrm{~cm}$. During the following years, despite the change of the crops, Cs-137 specific activities within the $10-20 \mathrm{~cm}$ layer remained slightly increased, but the difference with $0-10 \mathrm{~cm}$ layer (for the potato during 2015 - with both $0-10 \mathrm{~cm}$ and $20-30 \mathrm{~cm}$ layers) was insignificant. Minimal values of Cs-137 concentration during the entire period of observation were detected for the investigated site within the $20-30 \mathrm{~cm}$ layer. This, however, can be associated with a technical sampling problem - solution by uncontaminated material from the underlying A horizon below the deepest tillage sole shoe boundary. In general, the localization of the soil layer with increased Cs-137 specific activity parameters at $10-20 \mathrm{~cm}$ depth remains evident at the case study site throughout the observation period. However, a degree of heterogeneity of the isotope vertical distribution increases for crops with shallow cultivation techniques and decreases for crops with regular-depth rotational tillage.

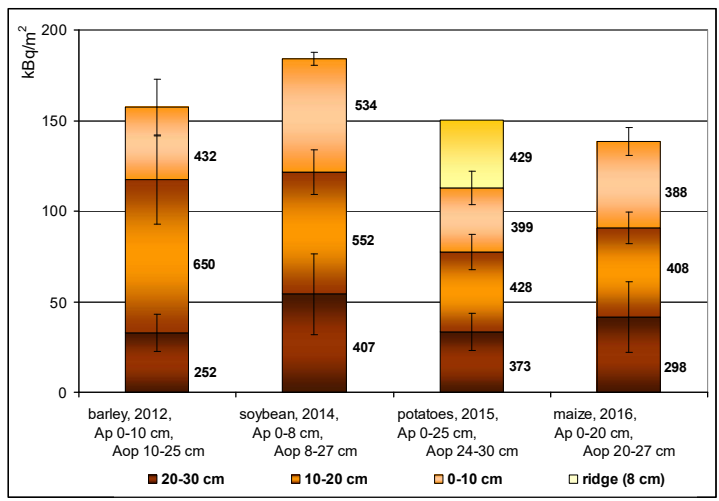

Figure 4. Variability of Cs-137 inventories $\left(\mathrm{kBq} / \mathrm{m}^{2}\right)$ within the $30-\mathrm{cm}$ topsoil layer of cultivated chernozem under changing cultures of the crop rotation. Confidence interval of mean values calculated for $\mathrm{P}=0.95$. The inscriptions alongside the bars show the specific activity of Cs- 137 .

For instance, under barley with shallow cultivation $10-20 \mathrm{~cm}$ layer contains about $54 \%$ of the total upper $30-\mathrm{cm}$ topsoil inventory, while for all other crops that value does not exceed $36 \%$. In contrast, under potato with sowing period cultivation to $\approx 25 \mathrm{~cm}$ depth maximum Cs-137 inventory is shifted upward, where the sowing ridge of $8-\mathrm{cm}$ high and upper $10 \mathrm{~cm}$ of plough layer together contain $48 \%$ of the total Cs- 137 inventory within a soil plough horizons.
3.5. Comparative analysis of vertical depth

distribution of Cs-137 and root biomass of cultural crops in plough horizons of cultivated chernozems of the Plavsk radioactive hotspot

The Cs-137 transfer from contaminated soils into vegetation largely depends not simply on its total content within the entire plough layer, but, in case of it uneven vertical distribution, on superposition of the isotope concentration peaks with layers of maximum rhizosphere density where radionuclide uptake actually takes place. The comparison of the vertical distribution of Cs-137 and underground biomass of cultures alternating within the crop rotation (Fig. 5) makes it evident that there are significant differences in this respect between different cultures. For barley and soya beans, more than $64 \%$ and $55 \%$ of the root biomass respectively is concentrated within the upper $10-\mathrm{cm}$ of the soil layer. At the same time, most of the Cs- 137 content under barley and soya beans $-54 \%$ and $37 \%$ of total inventory respectively - is stored within the 10-20 $\mathrm{cm}$ depth layer. Such relocation of the vertical profile distribution in combination with dominant rhizosphere development in the surface layer allow one to conclude that actual Cs-137 uptake by barley and soya beans from the contaminated plough layer will be even lower than could have been predicted basing on the isotope homogenous vertical distribution model.



Figure 5. Comparison of vertical distributions of Cs-137 and underground (root) biomass from the four different cultures from crop rotation within the $30-\mathrm{cm}$ cultivated topsoil layer of chernozem of the Plavsk radioactive hotspot

Strikingly different situation is observed for the potatoes. The most active Cs-137 uptake can take place in $10-20$ and $20-30 \mathrm{~cm}$ layers, where most of the medium and fine roots are concentrated (potato tubers mass was excluded from the consideration), while the isotope depth distribution is more or less uniform with insignificant concentration decrease downwards. Application of deep conventional rotation tillage for corn cultivation also determines a relatively uniform depth distribution of Cs-137 within the plough layer (up to 25-30 cm deep) with insignificant concentration 
T. Paramonova et al., Homo/heterogeneity of Cs-137 vertical distribution..., Rad. Applic., 2017, 2, 3, 192-199

decrease downwards, while most of the root biomass is contained within the upper $10-\mathrm{cm}$ layer. It must be noted, however, that for corn, on average, $59 \%$ of root biomass within the upper $10-\mathrm{cm}$ layer is represented by relatively large roots $(>2 \mathrm{~mm})$, while finer $(<2 \mathrm{~mm})$ roots become dominant at depths of $10-30 \mathrm{~cm}$ (on average $64 \%$ of fine roots within $20-30 \mathrm{~cm}$ layer). Hence, for potato and corn, it can be stated that the most active Cs-137 root uptake most likely takes place within the lower part of the plough layer, where its content is slightly decreased due to the deep conventional rotation tillage.

\section{CONCLUSIONS}

Morphological and gamma-spectrometric investigations of cultivated chernozem soils within the Plavsk radioactive Cs-137 contamination hotspot area proved that deep rotational tillage for radioecological rehabilitation purposes was carried out on agricultural lands of the region soon after the Chernobyl nuclear power plant accident in 1986 in order to minimize detrimental consequences of the atmospheric fallout contamination. That was major artificial mechanism of deep Cs-137 penetration into cultivated soil profiles to depths of 28-30 cm. Further impact of natural processes on Cs-137 vertical migration can be considered as negligible, as after 30 years passed since the contamination one can still observe that about $98 \%$ of the total isotope inventory in cultivated chernozems is stored within the plough layers limited to upper 30 $\mathrm{cm}$ of the topsoil. At the same time, under the conditions of variable crop rotations and changing cultivation practices depending on different crops over that time period, complete homogeneity of vertical Cs137 distribution cannot always be the valid approximation. Indeed, it depends on the crop and cultivation type used immediately prior to sampling. It is especially evident for cereals crops when layer with maximum Cs-137 content can often be located within 12-18 cm depth interval below the lower soil turnover limit of shallow cultivation operations applied in such a case.

Distribution of Cs-137 within the 30-cm topsoil layer is more or less steady during a growing period for individual crop. Changes of the vertical profile distribution pattern of Cs-137 in plough and old plough layers can reflect the changes in crop rotations and current cultivation techniques. It has been shown by direct observations that shallow surface cultivation for crops with most of the root biomass contained within the upper $10-\mathrm{cm}$ topsoil layer shifts the peak of Cs-137 content to the underplough $10-20 \mathrm{~cm}$ depth interval. This is typical for cereals and soya beans. When conventional deep rotation tillage $(20-25 \mathrm{~cm})$ is applied for row crops such as corn or potato, Cs- 137 vertical distribution becomes closer to uniform. In contrast, the zone of the most active root uptake for such crops is located in $20-30 \mathrm{~cm}$ layer. It can, therefore, be concluded that, in general, the existing cultivation practices are favorable for maintaining the superposition of the maximum active rhizosphere zone with maximum Cs-137 concentration zone as low as possible.
In terms of soil contamination assessment practices, it can be recommended that a systematic monitoring of cultivated topsoil conditions based on preliminary assessment of Cs-137 vertical profile distribution must be carried out in order to obtain reliable assessment of soil radioecological status. During this monitoring, agrotechnical specifics of different crops within the crop rotation should also be taken into account.

Acknowledgement: The study was conducted with the support from the Russian Foundation for Basic Research (project no. 14-05-00903).

\section{REFERENCES}

1. E. J. Evans and A. J. Decker, "Fixation and Release of Cs-137 in soils and soil separates," Canad. J. Soil Sci., vol. 46 , no. 3 , pp. $212-217,1966$. DOI: $10.4141 /$ cjss66-035

2. B. L. Sawhney, "Selective sorption and fixation of cations by clay minerals: A review," Clays Clay Miner., vol. 20, pp. 93 - 100, Apr. 1972. DOI: 10.1346/CCMN.1972.0200208

3. R. M. Cornell, "Adsorption of cesium on minerals: A review”, J. Radioanal. Nucl. Chem., vol. 171, no. 2, pp. $483-5$ O0, Jul. 1993. DOI: $10.1007 / \mathrm{BFO} 2219872$

4. R. M. Alexakhin et al., "Accident at the Chernobyl nuclear power plant," in Large radiation accidents: consequences and protective countermeasures, L. A. Ilyn, V. A. Gubanov, Eds., Moscow, Russia: IzdAT Publisher, 2004, ch. 3, pp. $330-386$.

5. Soil Sampling for Environmental Contaminants, IAEA-TECDOC-1415, IAEA, Vienna, Austria, 2004, pp. $7-39$.

Retrieved from:

http://www-

pub.iaea.org/MTCD/Publications/PDF/te_1415 web.p df

Retrieved on: Jan. 22, 2017

6. Remediation of sites with dispersed radioactive contamination, IAEA Technical Report Series No. 424, IAEA, Vienna, Austria, 2004, pp. 29 - 30.

Retrieved from:

http://www-

pub.iaea.org/MTCD/publications/PDF/TRS424 web.p df

Retrieved on: Jan. 23, 2017

7. Guidelines for remediation strategies to reduce the radiological consequences of environmental contamination, IAEA Technical Report Series No. 475, IAEA, Vienna, Austria, 2012, pp. 13 - 16, 22 - 23, 37 $38,126-131$.

Retrieved from:

http://www-

pub.iaea.org/MTCD/publications/PDF/trs475 web.pdf Retrieved on: Jan. 23, 2017

8. F. Bréchignac et al., "Controlled lysimetric simulation of accidents giving rise to radioactive pollution of the agricultural environment: Synthetic overview of research carried out at IPSN," Radioprotection, vol. 36, no. 3, pp. 1 - 26, Jul. 2001.

Retrieved from:

https://www.researchgate.net/publication/245276339 Retrieved on: Jan. 23, 2017

9. Атлас современных и прогнозных аспектов последствий аварий на Чернобыльской АЭС на пострадавших территориях России и Беларуси, Ю.А. Израэль и И. М. Богдевич, ред., Москва- 
T. Paramonova et al., Homo/heterogeneity of Cs-137 vertical distribution..., Rad. Applic., 2017, 2, 3, 192-199

Минск: Фонд «Инфосфера»-НИА-Природа, 2009, стр. 49 - 54. (Atlas of modern and forward-looking aspects of the consequences of the Chernobyl accident in the affected areas of Belarus and Russia, Yu. A. Izrael and I.M. Bogdevich, Eds., Moscow-Minsk: Fund "Infosphere"-NIA-Nature, 2009, pp. 49 - 54.)

Retrieved from:

http://rb.mchs.gov.ru/upload/site1/document file/oM qlw2bV2b.pdf

Retrieved on: Feb. 11, 2017

10. International soil classification system for naming soils and creating legends for soil maps, World Soil Resources Report 106, FAO, Rome, Italy, 2015. p. 101. Retrieved from:

http://www.fao.org/3/a-i3794e.pdf Retrieved on: May 2, 2017

11. T. Paramonova et al., "Modern parameters of caesium137 root uptake in natural and agricultural grass ecosystems of contaminated post-chernobyl landscape, Russia," Eurasian J. Soil Sci., vol. 4, no. 1, pp. 30 - 37, Jan. 2015.

Retrieved from:

http://gazi.dergipark.gov.tr/download/articlefile/62906

Retrieved on: Feb. 11, 2017

12. T. Paramonova and A. Tunik, "Cs-137 in aggregate fractions of arable chernozems: Plavsk radioactive hot spot, Russia," in Book of Abstracrs. $3^{\text {rd }}$ Int. Conf. Radiation and Applications in Various Fields of Research RAD 2015, Budva, Montenegro, 2015, p. 540. Retrieved from:

http://www.rad2015.radconference.org/pdf/Book\%20Abctracts\%20RAD\%2020 $15 . \mathrm{pdf}$

Retrieved on: Jan. 23, 2017
13. M. Ivanov, V. Golosov, E. Shamshurina, "Evaluation of optimal number of soil samples for detail reconstruction of initial field of ${ }^{137} \mathrm{Cs}$ fallout in Chernobyl affected areas," Eurasian J. Soil Sci., vol. 4, no. 4, pp. $227-233$, Oct. 2015.

Retrieved from:

http://dergipark.ulakbim.gov.tr/ejss/article/view/500 $\underline{0145555}$

Retrieved on: May 2, 2017

14. D. N. Lipatov, D. V. Manakhov, L. A. Vezhlivtseva, "Migration of radiocesium in lea and plowed soils of agricultural landscapes in Tula region," Moscow Univ. Soil Sci. Bull., vol. 58, no. 3, pp. 43 - 51, Jul. 2003.

Retrieved from:

https://www.researchgate.net/publication/261949494 Retrieved on: May 2, 2017

15. A. Angjeleska et al., "Determination of the vertical distribution of ${ }^{226} \mathrm{Ra},{ }^{232} \mathrm{Th},{ }^{4} \mathrm{~K}$ and ${ }^{137} \mathrm{Cs}$ in samples of cultivated soil taken in vicinity of certain cities in Republic of Macedonia," Agricult. Forestry, vol. 60, no. 3, pp. $97-106,2014$.

Retrieved from:

https://www.researchgate.net/publication/266202754 Retrieved on: Jan. 23, 2017

16. J. Koarashi et al., "Factors affecting vertical distribution of Fukushima accident-derived radiocesium in soil under different land-use conditions," Sci. Total Environ., vol. 431, pp. 392 - 401, Aug, 2012. Retrieved from:

https://www.researchgate.net/publication/227173596 Retrieved on: May 2, 2017 